\title{
Perspectives
}

\section{Reality, Dysconsciousness, and Transformations: Personal Reflections on the Ethics of Cross-Cultural Research}

Sandra Janusch

In this personal narrative, I offer reflections about the process of conducting a cross-cultural, cross-linguistic research project with teachers of English in China. Lessons learned from this study address some of the hegemonic perspectives and assumptions that can be dysconsicously held by native English-speakers, the value of crossing borders both literally and metaphorically to learn about others, and the reciprocal transformations that can occur when cultures and languages converge in research.

Dans ce récit personnel, j'offre des réflexions portant sur un projet de recherche interculturel et translinguistique avec des enseignants d'anglais en Chine. Les leçons qui découlent de ce projet touchent certaines des perspectives et des suppositions hégémoniques que les locuteurs natifs d'anglais peuvent garder inconsciemment à l'esprit; la valeur de traverser des frontières - littéralement et figurativement - pour mieux connaître les autres; et, les transformations réciproques qui ont lieu quand les cultures et les langues convergent en recherche.

Reality exists only through experience, and it must be personal experience. However, once related, even personal experience becomes a narrative. Reality can't be verified and doesn't need to be, that can be left for the "reality-of-life" experts to debate. What is important is life. Reality is simply that I am sitting by the fire in this room which is black with grime and smoke and that I see the light of the fire dancing in his eyes ... All that needs to be said is that outside, a mist is enclosing the green-blue mountain in a haze and your heart is reverberating with the rushing water of a swift-flowing stream. (Gao, 2001, p. 15)

\section{Introduction}

Throughout the past decade, China has been moving from a Confucian and Soviet-style pedagogical model toward the implementation of Western communicative language methodologies into its national English-language teach- 
ing curriculum (Hu, 2003; Leng, 1997). This new era in English-language teaching in China has mandated a change of paradigm for Chinese Englishlanguage teachers, requiring them to change more traditional teaching methodologies to reflect an ability-based model rather than a knowledgebased model of teaching and learning $(\mathrm{Hu})$. Increased professional development has been regarded as an important means to the advancement of the quality of English-language teachers in China and vital to the successful implementation of the new English-language teaching curriculum (Boyle, 2000; Cheng, Ren, \& Wang, 2003; Kennedy, 1996; Leng; Zuoyu, 2002).

An overseas professional development program focusing on communicative language methodology was conducted in Calgary in the fall of 2005 for a group of 23 teachers of English from Fujian Province. The course included approximately 150 hours of classroom training, observations of various local ESL classes in elementary and secondary schools, participation in a provincial professional development conference for ESL teachers, and lectures by academics and professional practitioners of ESL methodology. The participating teachers also lived with local families and took excursions to sites of cultural interest on weekends. This type of program is fairly representative of overseas professional development courses for non-native teachers of English offered in English-language-dominant countries today.

While this professional development course was being offered in Calgary, I was designing a study for my doctoral research in TESL. I decided to focus on the transformational learning experiences of this particular group of Chinese teachers from Fujian in four main areas of inquiry: their cultural knowledge and understanding; personal and professional identity; pedagogical knowledge; and oral language proficiency for teaching. My plan was to interview and videotape the teachers during their stay in Calgary and then travel to their schools in China six months later to reinterview and videotape them. The videotaped samples of lessons given by the participating teachers in Canada during the course and in China would provide a means by which to analyze changes to the teachers' oral language proficiency over time and in two distinct contexts. Through semistructured interviews conducted with the assistance of a bilingual interpreter, I hoped to develop an understanding of how the teachers attributed meaning over time to the knowledge gained from their overseas training experiences in Calgary.

Transformational learning theory (Mezirow, 1991, 2000, 2003) would provide a theoretical framework from which to analyze the teachers' described changes in the four areas of inquiry of my study. "Transformational learning occurs when, through critical reflection, an individual revises old or develops new assumptions, beliefs, or ways of seeing the world" (Cranton, 1994, p. 4). According to Mezirow, transformational learning is usually triggered by a problem or "activating event" and can, therefore, be a painful process to go through. After critical reflection and discussion, the person is compelled to 
change or to reorganize his or her ways of thinking about the problem and to take a course of action: he or she can no longer accept the old ways of thinking and behaving because of the new information gained through the reflective process. Overseas study and travel often require one to navigate through another set of social, cultural, and environmental structures, and as a result frequently involve episodes of frustration, anxiety, and personal reflection. The new English-language teaching curriculum required the Chinese teachers to adopt or transform their traditional practices as teachers, and the professional development course in Calgary would require them to participate in learning activities different from those that they had experienced in China and to reflect on how these differences affected their beliefs about teaching and learning. Transformation learning theory, therefore, seemed a natural fit from which to analyze the Chinese teachers' experiences in Calgary and to explain the lasting personal and professional changes that resulted from these experiences. I hoped that the outcomes of the study could offer some new paradigms about personal and pedagogical change in teachers and contribute to the global conversation on transformational learning achieved through international teacher education experiences.

After having lived in China for three years and abroad for many more than that, and after spending many hours reading about Chinese culture and the Chinese educational system in its past and current state, I felt quite ready to undertake this cross-cultural research project. Although not fluent in Mandarin, I still felt adequately prepared to understand my Chinese colleagues' lives, their feelings, the parameters of their professional contexts, and their thoughts about changes to their personal and professional identities. The teachers whom I would be interviewing had a high level of proficiency in English, and I would offer them the option of answering the interview questions in either English or Mandarin through the assistance of a bilingual, bicultural interpreter.

Through a review of the literature on the challenges of cross-cultural, cross-linguistic interviewing completed for my candidacy paper, I learned concepts such as emic and etic; insider and outsider; reflexivity and linguistic relativity (Bennett, 1998; Berry, 1989; Heyman, 1997; Kramsch, 1993; Mattingly \& Lawlor, 2000; Merriam \& Johnston-Bailey, et al, 2001; Tinsley, 2005). These ideas speak to the effect that the researchers' status, background, and linguistic knowledge can have on their ability to gather and interpret the words of others, and whether the researcher locates himself or herself inside or outside the participants' culture when interpreting the data. By the end of my paper, I had come to the conclusion that because of differences in age, education, race, ethnicity, language, religion, and life experiences, all research studies (to some degree) were essentially cross-cultural and that all researchers (to some degree) must be cross-cultural communicators. For someone who had spent most of her teaching career communicating across 
languages and cultures, I felt uniquely qualified to partake in research that would cross boundaries. I felt especially prepared because of my past experiences in China and the assistance of my interpreter, who would help me navigate throughout the data-collection phase.

The ultimate lessons of my study were not what I had anticipated when I designed it. In fact, what I really gained from the work was not found in the answers to my research questions, but rather in the new paradigms that I gained from the process of conducting the research itself. This process was far richer and more transformative than I had ever imagined it would be. My reflections from this experience are offered here as a personal narrative: my perspectives that were permanently reshaped through completing this complex, cross-cultural, cross-linguistic study.

\section{Lesson 1. Reality Exists Only Through Experience}

I arrived at the airport in Fujian Province full of excitement and optimism. I had arranged earlier to meet my interpreter, who was flying in from Beijing on an earlier flight. I had had no recent contact with her since I had left Canada, and when I landed, I did not see anyone in the arrivals hall carrying a sign with my name on it. Almost immediately, two young men and a woman approached me. In my broken Mandarin and through their smiles and nodding heads, I thought I understood that they had been sent to take me to the hotel where I would meet my interpreter. I collected my luggage and left with them in their vehicle down the highway in the dark of night toward the city of Fuzhou. From the questions they were asking me, I slowly began to realize that they had not been sent to pick me up at all, but instead were trying to become my local tour guides. Struck with panic, I was able to get them to turn the car around and take me back to the airport. They dropped me off, and I walked back into the arrivals hall to find my interpreter waiting for me. Filled with relief, I quickly realized in my brief introduction to Fujian that by naïvely getting into a car with strangers I could have been robbed, left alone on the side of the road in an unfamiliar city, or unthinkably, something much worse. It was clearly time to admit my limitations and to focus more clearly on what I did not know as opposed to what I thought I did know.

Besides the belief that I had a heightened ability to understand meaning across languages, some other assumptions that I carried with me on that trip involved those to which extensive reading of literature had led me. One of these questioned the appropriateness of Western pedagogies being transported to developing countries in order to improve their educational systems. Should we be forcing our "new" educational techniques and methodologies on those in other contexts with other needs? Although there may be legitimacy in this discussion, what I eventually came to observe in the schools that I visited in Fujian convinced me that such questions in rela- 
tion to China were irrelevant. In its recent efforts to modernize and reform, the Chinese education system has embraced Western pedagogy and curriculum in full force. Having previously lived in China, I knew that the rate of change in the country was traveling at the speed of light. I do not know how I had come to believe that the educational system would be different from almost every other area of modern Chinese life.

After visiting eight secondary schools in Fujian Province, I was impressed with many things, especially the collaborative nature of the teachers whom I met and the structure of their system, which supports and nurtures cooperation. The fact that I had not anticipated learning anything about Chinese schools, but instead was focused solely on exploring the teachers' professional development experiences in Canada, demonstrates certain hegemonic assumptions and subconscious feelings of superiority that were buried so deeply inside myself that I did not even know they were there. To some extent, the Chinese teachers and their students helped reinforce these ideas: in their schools, I was treated as a "foreign expert," and as one teacher told me, "If they hear it from you, they will believe it." In one school, the students actually asked for my autograph and e-mail address after I spoke, and because I was the first real native English-speaking person they had ever seen, a few just wanted to touch me.

I usually pride myself on my broad perspective and open-mindedness about other ways of living and viewing the world. I went to China with the best intentions of not being a "native-speaking cultural chauvinist" (Holliday, 2005a, 2005b) or "white-skinned teacher/researcher from rich communities (who) visit dilapidated classrooms of brown-skinned vernacular-speaking students in periphery communities" (Canagarajah, 1999, p. 51). The fact is that until contradictory information came to me through my experiences of visiting schools in China that challenged some of my deeply subconscious hegemonic perspectives, this is roughly who I had been. What I learned about the Chinese schools, which is reflected in most areas of development in China, is that the best of Western ideology and practice is being adopted and translated into the most appropriate version to work in the local Chinese context. In my opinion, the world will one day marvel at and learn from the results of this translation, especially in regard to education. How could I have been so naïve as not to have conceived of this possibility?

\section{Lesson 2. Lost in Translation}

As a person who has spent most of her career teaching and working overseas with students from diverse cultures, I assumed that conducting cross-cultural, cross-linguistic research would be easy for me. It was not: in many ways it was unnerving. I had a hard time letting go of control, allowing my interpreter to interject, interrupt, and converse with the teachers without my participation before and during the interview process. After all, it was my 
research that we were conducting; allowing it to evolve at times without my explicit input was difficult. Having to take on a more passive role in the research process while in China was uncomfortable and unfamiliar for me. I had to allow my interpreter to speak to people on my behalf, to participate in social exchanges where I could not get the humor or subtle cultural references: all I could do was surrender to the fact that in that environment I was a visitor, a foreign guest, an outsider. During the trip to China, my interpreter ultimately became my teacher, my collaborator, my homestay family, my friend. I soon realized that she was the lifeline into transforming my previous assumptions into something closer to the teachers' reality rather than my perceptions, and that if I was going to really try to learn about the people whom I was interviewing and videotaping, I would have to give in to the parameters of this unfamiliar context and let her be my guide.

Since conducting this research project, I have come to the conclusion that skepticism about the capacity of a researcher from one culture to describe accurately phenomena in other cultures is completely justified. I think that the perils of traversing lines between meaning and interpretation are tricky under the best of circumstances, and no matter how much we may think we know about what someone really means by what they say in another language, we are always working in the uncharted territory of "third places" (Kramsch, 1993). The fact that my perspective comes from another cultural orientation and a position of power and privilege makes the interpretation of meaning even more challenging. I eventually came to the conclusion that the only way I could possibly validate any attempt to write about the participating teachers in China was to proceed as did Holliday (2005a): "I do not therefore presume to be speaking for any of them. I speak only for myself, as someone who has worked with and learnt from them" (p. 306).

International cross-cultural research is challenged not only by factors of time, money, organization, and the crossing of languages and meanings, but also in the logistical reality that the context of the data-collection is gone after the researcher returns home. Correspondence with participants through email is difficult; the collaborative spirit in conducting the research and in the data-collection soon fades when one returns to one's own environment, and the researcher is left only with notes, videos, photographs, voices, and memories. It has been four years since I visited the teachers in their schools, and although I have many resources from which to draw, I am ultimately alone with my reflective memories of a time and place past. My interpretations of those experiences are no doubt altered through this time, distance, and otherness of context.

\section{Lesson 3. Outside the Box}

One question that I asked myself throughout this process was whether this type of professional development activity could be replicated in the teachers' 
home country. Overseas professional development is expensive and timeconsuming, and the quality of programs varies greatly among diverse countries and universities.

After completing this project, I now fully believe that overseas professional development for language teachers is irreplaceable: that it is multifaceted, complex, and distinctive. It provides for a range of learning opportunities far beyond what can be achieved in a classroom, the only element that could be replicated inside a host country. In the end, the unplanned, incidental learning experiences found in an overseas environment may prove to be the most significantly transformational of the learning opportunities in a professional development course. This belief is largely founded on reflections on my own overseas experiences in China while collecting the data for this research project.

In thinking about how teachers' understanding of cultural information was influenced by their experiences outside the classroom in Canada, I reflected on how much important information I had gained on the trip outside the realm of the designated data-collection process, the interviews and school visits. Most of what I really remember as significant came to me during casual discussions with the participating teachers, other teachers not involved in the study, and my interpreter. These conversations often occurred around the dinner table, on the bus traveling to a new city, while watching TV, in the teachers' room of the school between observations, and so forth. Because I intentionally reflected on the pieces of information gained through these incidental experiences and engaged in critical discourse about them with my interpreter, these unplanned moments in many ways turned out to be more transformational than those that were planned. The power of impromptu learning opportunities outside the planned, structured classroom learning activities distinguishes overseas professional development for language teachers in many ways from conventional professional development. It seems obvious to me now that investigating how to optimize these moments pedagogically is essential.

\section{Lesson 4. Language is Power}

Throughout the interview process, I wondered why I was having difficulty asking the teachers about changes to their own English-language proficiency and why they were having difficulty in responding specifically to questions in this area. The questions that I asked related directly to language proficiency in English felt to me like an intrusion of some form of highly personal knowledge. It felt embarrassing to be asking people about something that I knew was a source of insecurity for them and to which there was no concrete means for them to objectify their responses. I reflected on my own language proficiency (or lack thereof) in Mandarin and how difficult it is to discuss one's own abilities in performance-based activities. I realized that when 
someone asked me, "How good is your Chinese?" it was akin to their asking me, "How well do you sing? Dance? Parent?" The response inevitably has to be deferred to another question, Compared with what?

Realizing the ambiguity involved in trying to analyze one's own performance without reference to some quantifiable scale is the foundation behind a proposal for the development of an oral-language benchmarking system for EFL teachers that could be used as a self-assessment tool. The range between not good and excellent is too far and too tenuous to pinpoint without some sort of frame of reference. I believe that for non-native-speaking teachers of English, the lack of ability to articulate the level of their target-language skills keeps them permanently déclassé in the world of EFL. A benchmarking system focused on the oral language skills required for teaching EFL could perhaps help this issue. What would happen if we found out that oral language proficiency required for teaching EFL was not as complex as we imagined? Where would this leave the native/non-native teacher dichotomy?

King (1991) introduces the concept of dysconsciousness in "Dysconscious Racism: Ideology, Identity and the Miseducation of Teachers." In many ways this idea resembles Mezirow's (1991) subconscious meaning perspectives: paradigms that develop in people through childhood experiences and describe the attitudes, beliefs, and assumptions that people perceive as universals rather than products of a dominant culture. An example of this is the dominance of right-handedness, where things such as school desks, the placement of buttons on clothing, the shape of scissors, all of which go unnoticed by those of the dominant group who consider them normal, as well as the non-dominant group that considers the everyday adaptations that they have to make as normal. This explains how social privilege is manifested subconsciously in society.

Through my cross-cultural, cross-linguistics research study, I came to realize that as an educated Caucasian from Canada, not only does my ethnicity, education, and socioeconomic status grant me special privilege in the world, but so also does my mother tongue. Tacit understanding of the global position of English created my personal dysconsciousness about how this research project would unfold. Theoretically, I understood the concept of linguistic relativity, the power of language and culture to influence thought, but in practice I did not see its effect in this study. If I concluded that language, culture, and thought were inextricably connected, how could I suppose that I could really understand the perceptions of those in another culture without knowledge of their language? How could I presume to understand changes to their identities without understanding what their cultural concept of identity was and how it might be expressed in their language?

I somehow believed that through the assistance of an interpreter, I could overcome the chasms of language and cultural differences between the Chinese teachers and myself. In this regard, my interpreter not only had to trans- 
late their words, but also extremely complex concepts (e.g., identity) for which there was perhaps no direct translation across the two cultures. In retrospect, I now see my dysconsciousness as linguistic hegemony and language privilege. "To assume that there is no problem in interpreting concepts across languages is to assume that there is only one baseline, and that is the researcher's own" (Temple \& Edwards, 2002, p. 19). I wonder now as the dominance of the English spoken by native speakers recedes and as global economic power shifts from West to East, how will we (native English-speakers) reconstruct our identities in a left-handed world?

\section{Conclusion}

Transformational learning theory (Mezirow, 1991, 2000, 2003) states that deep learning can occur through the process of critical reflection after a period of discomfort or disequilibrium where prior knowledge or assumptions have been refuted or challenged. During my time in China, I could easily relate to the teachers' stories of their experiences in Canada. On my journey in China, I too experienced feelings of inadequacy, alienation, excitement, wonder, homesickness, fatigue, and affection just as the Chinese teachers had during their time in Canada. My understanding of Chinese culture, my personal and professional identity, my understanding of pedagogy, as well as my linguistic knowledge were transformed because of my experiences in China. I can only imagine how different the interpretations of this research would have been had I not gone to China to collect the data.

"The question of how close we can get to the reality of another culture in order to feel a part of its language and society is also a question of how much we want to learn about ourselves from this encounter" (Szwaj, 1999). I did not plan on learning anything about myself when I planned this study. In fact, I thought I pretty well knew as much as I needed to know about China and my own intercultural skills when I designed the study. Just as the teachers whom I interviewed described how the professional development course in Canada had made a lasting effect on their lives, when I returned from China, unpacking the paradigms that I had taken with me permanently altered the lens through which I view the world and my place in it. I was seeking evidence of transformational learning from Chinese teachers and in turn found myself transformed. Perhaps the lessons that I have learned in this study will challenge others to take up research that explores the lives of those from other cultures and languages and bring us all closer to understanding the possibilities that crossing borders can achieve.

\section{The Author}

Sandra Janusch is currently the Instructor and Field Advisor for the Transitions to Alberta Classrooms Program (TAC) for immigrant teachers in Calgary. This professional bridging program is offered through a partnership with the University of Calgary and the Calgary Board of 
Education. Sandra received her doctorate in TESL from the University of Calgary in 2007 and has been an ESL educator for over 25 years in France, China, Vietnam, Indonesia, the United States, and Canada.

\section{References}

Adamson, B., \& Morris, P. (1997) The English curriculum in China. Comparative Education Review, 41(1), 3-26.

Bennett, M. (1998). Intercultural communication: A current perspective. In M. Bennett (Ed.), Basic concepts of intercultural communication (pp. 1-34). Yarmouth, MA: Intercultural Press.

Berry, J. (1989). Imposed etics-emics-derived etics: The operationization of a compelling idea. International Journal of Psychology, 24, 721-735.

Boyle, J. (2000). Education for teachers of English in China. Journal of Education for Teaching, 26(2), 147-155.

Canagarajah, A.S. (1999). Resisting linguistic imperialism in English teaching. Oxford, UK: Oxford University Press.

Cheng, L., Ren, S., \& Wang, H (2003). Pre-service and in-service teacher education of secondary English language teachers in China. TEFL Web Journal, 2(1), 1-14.

Cranton, P. (1994). Understanding and promoting transformational learning. San Francisco, CA: Jossey-Bass.

Gao, X. (2001). Soul mountain, London: HarperCollins.

Heyman, R. (1997). How talk makes sense. Why didn't you say that in the first place? How to be understood at work. San Francisco, CA: Jossey-Bass.

Holliday, A. (2005). How is it possible to write? Journal of Language, Identity and Education, 4(4), 304-309.

Holliday, A. (2005). The struggle to teach English as an international language. Oxford, UK: Oxford University Press.

$\mathrm{Hu}, \mathrm{G}$. (2003). English language teaching in China: Regional differences and contributing factors. Journal of Multilingual and Multicultural Development, 24(4), 290-318.

Kennedy, D. (1996). The role of the foreign language teacher as agent of change and implications for teacher education programmes in Chinese teacher training college. ELTED, 2(1), 52-65.

King, J.E. (1991). Dysconscious racism: Ideology, identity and the miseducation of teachers. Journal of Negro Education, 60(2), 133-146.

Kramsch, C. (1993). Context and culture in language teaching. Oxford, UK: Oxford University Press.

Leng, H. (1997). New bottles, old wine: Communicative language teaching in China. English Teaching Forum, 35(4), 38-41.

Mattingly, C., \& Lawlor, M. (2000). Learning from stories: Narrative interviewing in crosscultural research. Scandinavian Journal of Occupational Therapy, 7, 4-14.

Merriam, S., \& Johnston-Bailey, J., et al. (2001). Power and positionality: Negotiating insider/outsider status within and across cultures. International Journal of Lifelong Education, 20(3), 405-416.

Mezirow, J. (1991). Transformative dimensions of adult learning. San Francisco, CA: Jossey Bass.

Mezirow, J. (2000). Learning to think like an adult: Transformational theory: Core concepts. In J. Mezirow \& Associates (Eds.), Learning as transformation: Critical perspectives on a theory in progress, San Francisco, CA: Jossey-Bass.

Mezirow, J. (2003). Transformative learning: Theory to practice. Transformative learning in action. New Directions for Adult and Continuing Education, 74, 5-12.

Szwaj, M. (1999). The paradox of a non-native EFL teacher. Humanising Language Teaching, 1 (8). Retrieved March 10, 2007, from: http:/ /www.hltmag.co.uk/dec99/mart.htm 
Temple, B., \& Edwards, R. (2002). Interpreters/translators and cross-language research: Reflexivity and border crossings. International Journal of Qualitative Methods, 1(2), 1-22. Tinsley, C. (2005). The heart of darkness: Advice on navigating cross-cultural research. International Negotiation, 10, 183-192.

Zuoyu, Z. (2002). The teaching profession: To be or to do? Journal of Education for Teaching, 28(3), 211-215. 